\title{
LA COLECCIÓN DE PAPELES VARIOS DEL ARCHIVO HISTÓRICO DE LA UNIVERSIDAD DE SALAMANCA. ANÁLISIS DE LA DOCUMENTACIÓN: PROCEDENCIAS, CARACTERÍSTICAS E IMPORTANCIA HISTÓRICA
}

\author{
Agustín Vivas Moreno*
}

\section{Introducción}

Los Papeles Varios ${ }^{1}$ del Archivo Histórico de la Universidad de Salamanca ${ }^{2}$ son una sección facticia o colección documental, esto es, un conjunto de documentos reunidos según criterios no objetivos, y que por lo tanto, no conservan una estructura orgánica ni responden al principio de procedencia archivístico. En consecuencia, se trata de un conjunto de documentos -hasta ahora sin tratar archivísticamente- reunidos de forma facticia por motivos de conservación debido a su especial interés histórico.

En este orden de cosas, las páginas que siguen intentarán analizar dicha documentación estableciendo cuáles son sus características principales. Intentaremos evidenciar, por consiguiente, qué tipología documental encontramos, cuáles son las procedencias de mayor relieve, qué cronología abarcan los documentos, qué importancia histórica merecen, etc. En consecuencia, pretendemos extraer una serie de rasgos generales válidos para toda la colección documental, dejando para otra ocasión análisis pormenorizados y más exhaustivos. ${ }^{3}$

*. Facultad de Biblioteconomía y Documentación. Universidad de Extremadura.

1. En adelante P.V.

2. En adelante A.U.S.A.

3. Para ello, vid. mi tesis doctoral: Fondos documentales del Archivo Histórico de la Universidad de Salamanca La Colección de Papeles Varios; análisis descriptivo, tesauro y gestión documenta automatizada. Salamanca, 1998. 6 vols. Dedicados a la Colección de Papeles Varios: Vol. II (Características generales de la Colección y análisis pormenorizado de los P.V. 1 al P.V. 50; Vol. III y Vol. IV. Catálogo documental de los P.V. 1 al P.V. 50; Vol. V. Tesauro para los P.V. 1 al P.V. 50; y Vol. VI. Análisis pormenorizado de los P.V. 51 al P.V. 277). 


\subsection{Secciones facticias. Características}

No hay oficina sin un "cajón de sastre", ni archivo que no tenga documentos sueltos que por su dificultad de lectura, mutilación, hongos, o procedencia desconocida, no hayan sido amontonados sin identificación alguna, bajo denominaciones inconcretas, como Extravagante, Indiferente General, Fechos, Infierno, Varios, Papeles Varios, y otras semejantes. Como las tareas de clasificación e inventario de la documentación seriada absorve casi la totalidad de todo el tiempo de que disponen los archiveros, raramente hay ocasión de inventariar o catalogar la documentación dispersa. ${ }^{4}$

Así pues, "dichas colecciones documentales son agrupaciones documentales realizadas voluntariamente en los archivos a partir de sus fondos y que responden a motivos de conservación o instalación, determinados habitualmente por sus soportes o por su grafía"s, aunque no han faltado en el origen de su formación algunas razones subjetivas y arbitrarias que han movido a los archiveros en determinadas épocas a agrupar los documentos en razón de un tema para destacar su importancia. ${ }^{6}$ En otras ocasiones, los múltiples ingresos históricos extraordinarios de documentación -donaciones, legados, reintegraciones, depósitos o comprasprocedentes de variadas instituciones, y llevados a cabo sin rigor alguno, han amontonado papeles de diversas fechas, lugares y procedencias, que hacen imposible la averiguación de sus itinerarios históricos hasta la ubicación en el archivo. No responden, por consiguiente, al principio de respeto natural de los fondos ni al principio de procedencia, según los cuales "se deben mantener agrupados, sin mezclar con otros, los documentos provenientes de una administración, de un establecimiento, o de una persona natural o moral determinados" ${ }^{\prime \prime}$. Se trata, pues,

4. Con muy poca frecuencia se tratan archivísticamente estas colecciones. Normalmente se trata de catálogos y ediciones de fuentes que transcriben íntegramente el conjunto documental cuyo nexo de unión suele estar en el tema o en el ámbito geográfico. En consecuencia, se trata de instrumentos de descripción extensos y costosos, tanto por el tiempo que supone hacerlo, como por la dificultad que supone el enfrentarse con documentación de muy distinto signo, o por el importe elevado de la edición. Además, existe una opinión bastante generalizada, según la cual, estos costos no suelen compensar la utilidad que de ellos se hace. De aquí que estas colecciones no sean punto obligado en una programación descritiva. Sí contamos con algunos ejemplos: MATILLA TASCÓN, A.(dir.). Archivo Histórico de Protocolos de Madrid. Papeles Sueltos. Inventario. Madrid: Ministerio de Cultura, 1987; GIL MERINO, A. (dir.). Catálogo de la Sección de Varios del Archivo Histórico Provincial de A/La Coruña. Ha sido reorganizado por procedencias. Además, se han realizado diversos catálogos por procedencias extraídos de la sección de Varios. Dejamos al margen las colecciones voluntarias confeccionadas por documentos cuya unión y relación entre ellos la determina bien un tema o asunto, bien el coleccionista o autor de la colección. En este orden de cosas, es bastante corriente encontrar colecciones de mapas, planos, estampas, dibujos, fotografías, diplomas, etc. (Cfr. PESCADOR DEL HOYO, C. El Archivo: instrumentos de trabajo. Madrid: Norma, 1993).

5. Por ejemplo, Sección de Mapas del Archivo Histórico del Reino de Galicia (Ibidem, p. 28).

6. Por ejemplo, la Sección de Patronato del Archivo General de Indias (A.G.I.) (Ibidem).

7. DUCHEIN, M. "El respeto de los fondos en Archivística. Principios teóricos y problemas prácticos". En: WALNE, P. (rec.). La Administración moderna de archivos y la gestión de docu- 
de colecciones antiarchivísticas. $Y$ es que, por desgracia, no siempre es posible proceder a la reconstitución del orden originario. El investigador puede encontrarse frente a lagunas y perturbaciones de tal amplitud, a una tal desaparición de elementos determinantes, que ya no le es posible averiguar cuál era el orden originario o la procedencia de los papeles. Rota la organicidad del archivo y convertido en colección documental, nos deberemos preguntar por las primordiales procedencias de dichos documentos.

En consecuencia, la procedencia de la documentación de las secciones facticias suele ser múltiple y difusa. Múltiple, por cuanto reúnen documentos generados o producidos por distintas instituciones y organismos; y difusa, por la presencia de documentación ambigua e indeterminada, mezclada con otra de características claras y precisas, de la que no acabamos de obtener un conocimiento exhaustivo de su procedencia y de su íter hasta llegar a estas colecciones.

Fruto de esta ambigüedad documental confusa e incierta, es característica corriente de estas secciones facticias la no diferenciación precisa y rigurosa entre documentación archivística y material librario o de biblioteca. En otras palabras, es frecuente, y nosotros así lo hemos atestiguado, que junto a documentos de archivos se hallen ejemplares librarios que responden a material que debieran estar por sus características ubicados en una biblioteca.

En otro orden de cosas, estas colecciones documentales misceláneas se caracterizan por la falta de uniformidad en las unidades de instalación. Es habitual encontrarnos en la misma colección con diversas unidades documentales heterogéneas reunidas para su conservación y colocación en el depósito en cajas, carpetas, legajos, etc. Incluso, en algunas ocasiones, encontraremos volúmenes que han sido encuadernados generalmente en fechas más tardías a la de la producción documental, agrupando documentos de diversa procedencia, cronología o temática.

Por último, otra de las características de estas secciones facticias suele ser la amplitud temática, geográfica, cronológica y documental. Producto de la múltiple procedencia documental y de los accidentados itinerarios históricos de los documentos que componen las secciones de "Misceláneas", "Varios" y "Papeles Varios", la temática, cronología,geografía y tipología documental de dicha documentación suele ser dilatada y extensa. En nuestro caso, tal y como explicaremos más abajo, hemos hallado documentación de muy diversa temática -Educación y Cultura, Estado y Gobierno, Derecho y Justicia, Economía, Población y Sociedad, Iglesia y Religión, etc.-, de diversos momentos históricos -siglos XVII, XVIII y XIX-, de diversos lugares -Corona de Castilla, Corona de Aragón, Reino de Inglaterra, Estados Pontificios, etc.-y de múltiples tipologías documentales -Reales Cédulas, Bulas Pontificias, Breves Pontificios, Concordias, Cartas acordadas,

mentos. París: UNESCO, 1985, p. 69. (Cit. por CRUZ MUNDET, J.R. Manual de Archivística. Madrid: Pirámide, 1994, p. 47). 
etc-. En definitiva, son rasgos propios de estas colecciones, fruto de su agrupación según criterios subjetivos, la miscelaneidad temática, la amplitud cronológica, la diversidad regional y la vastedad documental.

En conclusión, el tratamiento archivístico de estas colecciones documentales o secciones facticias es sumamente complejo. Fruto de toda esta problemática han sido frecuentemente aisladas en el tratamiento archivístico y en la planificación descriptiva de los Archivos, hasta tal punto que su consulta en múltiples ocasiones ha sido imposibilitada. La mayoría de las veces ni siquiera se conocen los documentos que se ubican en dichas secciones, pues nadie los ha verificado o examinado. No tienen ni signatura. La carencia de un análisis de esta documentación y la ausencia de un trato archivístico a estas colecciones -identificación, clasificación, ordenación, métodos de notación, descripción- son características habituales en los archivos.

Siendo conscientes de la dificultad que entraña el análisis archivístico de estas colecciones, pero movidos por la importancia histórica que de forma usual presenta la documentación aquí ubicada -que hace de ellas, reductos muy útiles para historiadores especializados en determinadas temáticas- nos disponemos a analizar la Colección de P.V. del A.U.S.A. Nos enfrentaremos a la imposibilidad de la reconstitución del orden originario de la documentación y a su procedencia, a la desaparición de elementos determinantes para la investigación de la estructura orgánica que generó la documentación y a la destrucción de la organicidad del archivo que impide el estudio del método histórico. No obstante, intentaremos desentrañar las procedencias de mayor relieve y estudiar e identificar la documentación aquí ubicada.

\subsection{Estado de la cuestión}

Nada conocemos publicado para la Colección de Papeles Varios del Archivo Universitario de Salamanca, ni tan siquiera de forma indirecta e incompleta.

Lo único realizado al respecto, que conozcamos, es nuestra tesis doctoral ${ }^{8}$. En ella analizamos pormenorizadamente la Colección y a ella nos remitimos para completar de modo exhaustivo lo que aquí expongamos. Por otra parte, fui invitado al $\vee$ Congreso Internacional de Universidades Hispánicas en el que participé con una ponencia acerca de la metodología para el estudio de la Colección de P.V. del A.U.S.A., sus objetivos y características. ${ }^{9}$ Asimismo, como fruto de las investigaciones realizadas en el marco de la realización de una tesi-

8. Fondos documentales del Archivo Histórico de Salamanca. La Colección de Papeles Varios... Op. Cit.

9. "La colección documental de Papeles Varios del Archivo Histórico de la Universidad de Salamanca" en RODRÍGUEZ-SAN PEDRO BEZARES, L.E. (Ed.). "Las Universidades Hispánicas: de la Monarquía de los Austrias al Centralismo Liberal". Actas del V Congreso Internacional de Universidades Hispánicas. Salamanca: Universidad de Salamanca; Junta de Castilla y León, 1999. Vol. II, pp. 405-424. 
na de licenciatura en Historia realicé algunas indagaciones que tuvieron como objeto la Historiografía de la Secesión de Portugal y la publicística de la Restauraçao Portuguesa en 1640, teniendo como base fundamental de trabajo la importante documentación hallada al respecto en la sección de Manuscritos de la Biblioteca Universitaria de Salamanca y en la colección de Papeles Varios del Archivo Universitario. De este modo, el año 92 presenté como ponencia al Congreso Hispano-Portugués sobre "Las Relaciones entre Portugal y España en la Época de los descubrimientos y la expansión colonial" una ponencia que analizaba la documentación ubicada en la sección de Papeles Varios relativa al Portugal de los Felipes (1580-1640). Publicación que más tarde completé con otros trabajos presentados a diversos Congresos y Jornadas. ${ }^{10}$

Por otra parte, la Colección de Papeles Varios ha sido mínimamente utilizada como base de otras investigaciones históricas. Conocemos al respecto el uso que hace de esta colección Juan Luis Cortina Iceta para el estudio de la biografía y la obra del Jesuita Luis de Losada y Prada. En este caso se sirve de los P.V. 34, P.V.45, P.V.49, P.V.53, P.V.64, P.V.68, P.V.70, P.V.74, P.V.94 y P.V.100 donde el autor encuentra algunas obras de Luis de Losada. ${ }^{11}$ Del mismo modo, la colección fue utilizada mínimamente por Daniel Simón Rey para el estudio de las Facultades de Artes y Teología de la Universidad de Salamanca en el siglo XVIII, citando exclusivamente como fuente el P.V.34. ${ }^{12}$ Otros autores han citado

10. VIVAS MORENO, A. "Historiografía de la Secesión de Portugal en los fondos documentales (Mss. Y P.V. ) de la Biblioteca Universitaria de Salamanca. Una primera aproximación al tema". En: CARABIAS TORRES, A. Mํ. (ed.) Las relaciones entre Portugal y Castilla en la época de los descubrimientos y la expansión colonial. Salamanca: Univ. de Salamanca, 1994; La secesión de Portugal en el Archivo Universitario de Salamanca: La Sección de Papeles Varios, Badajoz, 1995; La Restauraçao portuguesa y la Sección de Papeles varios del Archivo Universitario de Salamanca. Argumentaciones ideológicas del discurso historiográfico. Badajoz, 1996; Literatura política y panfletaria en la Restauraçao portuguesa: el ejemplo la sección de Papeles Varios del Archivo Universitario de Salamanca. Badajoz, 1998.

11. CORTINA ICETA, J. L. El siglo XVIII en la Pre-Ilustración Salmantina. Vida y pensamiento de Luis de Losada (1681-1748). Madrid, 1981. Aparte de los Papeles Varios que cita el autor, hay obras de Luis de Losada en los P.V. 37, P.V 38, P.V. 46 y P.V.50. Al margen, encontramos abundantes referencias indirectas a este fraile Jesuita en otras unidades de instalación.

12. SIMÓN REY, D. Las Facultades de Artes y Teología de la Universidad de Salamanca en el siglo XVIII. Salamanca: Univ. de Salamanca, 1981. Esta obra se caracteriza por el esmero con que se realiza uno de los pocos intentos de catálogos de profesores del Estudio salmantino, en este caso con la realización de un análisis bio-bibliográfico de los catedráticos del s. XVIII en las Facultades de Teología y Artes. Sin embargo, en este sentido, consideramos que se hace un uso muy exiguo de la colección de Papeles Varios, pues hay entre nuestros documentos innumerables obras de los profesores de estas Facultades, que a buen seguro al autor le hubiera deseado conocer. (Vid. al respecto el estudio en el Cap. 7 de nuestra tesis doctoral, al efectuar el análisis de contenido y la importancia para la investigación histórica de los P.V. 51 al P.V. 277 (Fondos documentales del Archivo Histórico de la Universidad de Salamanca. La Colección de Papeles Varios... Op. Cit. Cap. 7.2.5.). 
algún volumen de Papeles Varios en alguna de sus obras. Es el caso de José Barrientos García ${ }^{13}$-autor que conoce bien la Colección- o Bénédicte Pons. ${ }^{14}$

Al margen, Vicente de la Fuente y Juan Urbina, en su catálogo de manuscritos de la Biblioteca Universitaria de mediados del s. XIX, citan algunos volúmenes procedentes de la Biblioteca de los Jesuitas y más concretamente del Padre Pedro Abarca. En este sentido, se mencionan 6 tomos de "relaciones y papeles varios", que nosotros hemos localizado en P.V., y que se corresponden con los P.V. 2, P.V. 3, P.V. 4, P.V. 5, P.V. 14 y P.V. $15 .{ }^{15} \mathrm{Al}$ mismo tiempo, se refiere la presencia de un tomo en tamaño folio, algo deteriorado e incompleto, también procedente del Jesuita Padre Pedro Abarca, que se corresponde con el P.V. 7. ${ }^{16}$ Por último, se alude a otros tomos de este mismo autor que reúnen en su mayoría papeles históricos escritos de su puño y letra, consultas y papeles sobre asuntos de Teología Moral y Derecho Canónico, documentos relacionados con Genealogías y linajes, y "Memoriales presentados a su Magestad en orden al bien de la República", en parte encontrados en dicha sección de Papeles Varios - como en el P.V. 6-, y en parte localizadas en la Sección de Manuscritos de la Biblioteca Universitaria ${ }^{17}$. En definitiva, Vicente de la Fuente y Juan Urbina reú-

13. BARRIENTOS GARCíA, J. Un siglo de moral económica en Salamanca (1526-1629). Salamanca, 1985, etc.

14. PONS, B. Sous les Habsbourgs I'Université de Salamanque en fête. Étude des sources. Mémoires de Dea, 1986. Université Paris-Sorbonne IV.

15. "Relaciones y papeles varios, manuscritos e impresos: recogidos por dicho Padre. Seis tomos en folio, pergamino. El $1^{\circ}$ contiene varios tratados sobre asuntos teológicos. El $2^{\circ}, 3^{\circ}$ y $4^{\circ}$ contienen mezclados manuscritos e impresos. El $5^{\circ}$ contiene papeles relativos á varios puntos de la S. Escritura. El $6^{\circ}$ es de genealogías impresas, anotadas al margen por dicho Padre: contiene las de los Abarcas, Garcipolleros, Suárez de Toledo, Zúñiga y otros" (FUENTE, Vicente de la y URBINA, Juan. Catálogo de los libros manuscritos que se conservan en la Biblioteca de la Universidad de Salamanca. Salamanca, 1855. Pág. 9)

16. "Id. Papeles Varios, que dejó en la Biblioteca de Jesuitas de Salamanca. Un tomo en folio, algo deteriorado, con 395 pág[inas] dob[les], pero faltan las 144 primeras. Tiene índice de materia". (Ibídem, p. 2).

17. "Genealogías de los Reyes de Aragón, Navarra, Córdoba, etc. Está en el mismo el advertimiento particular de Antonio Pérez, sobre el hecho de su causa, para información de los $S\left[\right.$ eñor] es Jueces, papel curioso y de letra del siglo XVI. Un tomo en $4^{\circ}$ bien conservado [...]

$I d[\mathrm{em}]$ Papeles históricos, casi todos escritos de su mano. Hay entre ellos los reparos al libro del Cristianismo interior: otro sobre la intervención de la Santa Cruz y la historia de los Gerifes de África.Un tomo en $4^{\circ}$, hol[andesa].

$I d[\mathrm{em}]$ Dogmatica et moralia. Un tomo en $4^{\circ}$ algo deteriorado. Contiene noticias y cartas sumamente curiosas y algunas de ellas relativas a la Universidad de Salamanca. Apenas tiene nada de Teología,pero se le ha conservado el título, que tiene en la parte esterior.

$I d[\mathrm{em}]$ Dogmatica varia. Bajo este epígrafe se contienen varios tratados curiosos en latín sobre algunos errores del siglo XVII,especialmente de los Jansenistas y Probabilistas. Un tomo en $4^{\circ}$ con 345 pág[inas] dobles.

Id[em] Moralia quaedam. Es una colección de consultas y papeles curiosos sobre varios asuntos de Teología Moral y Derecho Canónico. Entre ellos hay un informe sobre el estado de los Colegios Mayores y sus abusos en tiempos del Conde de Oropesa 81685); otro informe contra el genio apasionado y duro del P. Francisco Reluz, Dominico, confesor de Carlos II y ene- 
nen todas las obras manuscritas de Pedro Abarca (S.I.) hoy repartidas entre la Sección de Papeles Varios del Archivo Universitario y la Sección de Manuscritos de la Biblioteca Universitaria.

Por otra parte, la Colección de Papeles Varios ha estado hasta el momento fuera de la programación y planificación descriptiva del Archivo, hasta tal punto, que no ha recibido ningún tratamiento archivístico. Es lógico que encontrándose abundante documentación seriada en espera de tareas de clasificación, ordenación e inventarización -tal es el caso, por ejemplo, del importante fondo de la Audiencia Escolástica- no haya habido ocasión de tratar archivísticamente la documentación dispersa, que en rigor debiera dejarse para el final de la programación descriptiva.

Lo único con lo que contamos es con un fichero no accesible al público desordenado, confuso y anárquico. ${ }^{18}$ Se nos ofrece un producto inconcluso e inacabado, en muy abundantes casos de resultados defectuosos y parciales, y con una rentabilidad variable y cambiante. En definitiva, un fichero incompleto, desigual, defectuoso y fragmentario. Veámoslo rápidamente ${ }^{19}$ :

- Fichero Incompleto: De las 206 unidades de instalación que se conservan, el fichero sólo dispone de fichas para 101, y no dispone para 105. Pero el problema no acaba ahí. De las 101 unidades de instalación de las que el fichero sí dispone de fichas, en una abrumadora mayoría -casi un 75\%están incompletas. En definitiva, sólo un 12,62\% de las unidades de instalación quedan reflejadas íntegramente en el fichero, sin que esto signifiqure que no se presenten algunos errores.

- Fichero desigual. Las fichas de que dispone el fichero han sido confeccionadas en diversas fechas y momentos históricos, lo cual implica una falta de uniformidad entre ellas, fruto de seguir, para cada caso, distintas normalizaciones catalográficas. Mientras unas, que fueron realizadas en el primer tercio del siglo, son defectuosas, incompletas, con abundantes errores y con muy pocos datos, otras, por el contrario, realizadas más recientemente presentan un elevado rigor catalográfico.

- Fichero defectuoso: El fichero se encuentra lleno de errores. Dichas inexactitudes presentan esencialmente esta doble tipología: abundantes documentos presentes en las unidades de instalación de los que el fichero no dispone

migo de los Jesuitas de Salamanca; un discurso acerca de la exclusiva que gozan los Reyes Católicos en el cónclave, escrito por el Padre Nicolás Martínez, Catedrático de Prima del Colegio Romano al servicio del Cardenal Aquaviva, en 1662. Un tomo en $4^{\circ}$ bien cons[ervado] con 423 pág[inas] dobles." (Ibídem, p. 10).

18. Agradecemos la gentileza de la dirección del Archivo, concretamente en la persona de su Director D. Severiano Hernández, por habernos dejado acceder al fichero para su consulta.

19. Para un análisis exhaustivo del fichero, Vid. Cap. 3.1.2. de nuestra tesis doctoral "Estado de la Cuestión" en Fondos documentales del Archivo Histórico de la Universidad de Salamanca. La Colección de Papeles Varios... Vol. II, págs. 8-21. 
de fichas ${ }^{20}$ y documentos que el fichero coloca en una determinada unidad de instalación cuando en realidad están en otra ${ }^{21}$. Curiosamente, en algunos casos, hemos encontrado documentos citados en el fichero, ausentes en las unidades de instalación. ${ }^{22}$ Dichos errores se multiplican indefinidamente en las fichas más antiguas, lo que nos hace aconsejar, incluso, en estos casos, su no consulta para no llegar a conclusiones inexactas e incorrectas.

Así pues, el panorama hasta ahora venía siendo desolador, por no decir inexistente. No había ningún trabajo de investigación que supusiese un acercamiento histórico o documental a la colección de Papeles Varios. Del mismo modo, por lo que respecta al tratamiento archivístico, la sección facticia se había mantenido completamente al margen de la programación y planificación descriptiva del archivo.

\section{Características generales}

1. La colección documental de P.V. está compuesta por 279 unidades de instalación, de las cuales se encuentran disponibles 206 (73, 83\%), faltando, por consiguiente 73 (26,17\%). La última unidad de instalación localizada lleva por signatura P.V. 277, pero hay dos parejas de P.V. que llevan signaturas iguales y que corresponden a los P.V. 196 y P.V. 211.

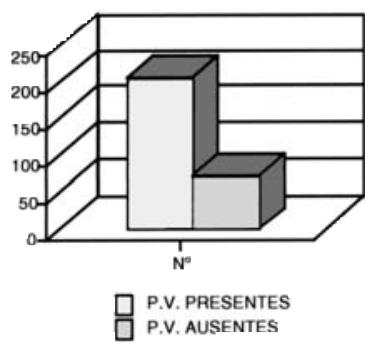

\begin{tabular}{|c|c|c|}
\hline \multicolumn{3}{|c|}{ P.V. } \\
UNIDADES DE INSTALACIÓN PRESENTES Y AUSENTES \\
\hline & № & $\%$ \\
\hline P.V. PRESENTES & 206 & 73,83 \\
\hline P.V. AUSENTES & 73 & 26,17 \\
\hline TOTAL & 279 & 100 \\
\hline
\end{tabular}

\section{Figura 1}

Todas las ausencias se encuentran localizadas desde el P.V. 151 hasta el P.V. 277, ubicándose el mayor área de ausencia en el grupo que va desde el P.V. 201

20. Por ejemplo, están ausentes en el fichero, entre otros muchos, los documentos P.V. 4-30, acerca de un papel sobre el brazo de los Caballeros en la Corte, o P.V. 7-75, acerca de una carta de un curial de Roma residente en dicha ciudad, respondiendo a otra en lo tocante al indulto que pretende Don Francisco de Villaveta. Evidentemente los errores son innumerables cuando se hace referencia a unidades de instalación que están descritas con fichas de los años 40.

21. Por ejemplo, el fichero dice que en el P.V. 226 encontramos un contrato de encabezamiento general para los años 1578, 1579, 1580 y 1581, cuando en realidad lo encontramos en el P.V. 229. Del mismo modo, el fichero dice que en el P.V. 264, encontramos un Memorial de la Universidad de Zaragoza sobre el pleito que mantenían las Iglesias de La Seo y la del Pilar de Zaragoza, cuando en realidad lo encontramos en los P.V. 218 y 265.

22. Por ejemplo, un manifiesto presentado por el Duque de Escalona, en P.V. 230. 
hasta el P.V. 250. La falta de estos P.V. puede ser explicable por varias razones: por la presencia de muchos de ellos en el fondo antiguo de la Biblioteca de la Universidad de Salamanca; por la pérdida de algunos legajos,ya sea por la mala conservación en determinadas ocasiones, ya sea fruto de las idas y venidas con que se han visto padecidos, o por su deficiente y múltiple signaturización; y, por último, por su abandono y descuido, ya que es bastante lógico pensar-por lo que más abajo demostraremos- que algunos legajos que faltan reunieran simplemente algún que otro documento infinitamente repetido, por lo que su interés archivístico e histórico fuera menor.

2. Existen dos tipos de unidades de instalación: el volumen encuadernado $(69,42 \%)$ y el legajo $(30,58 \%)$. Los volúmenes, en la mayoría de los casos, aparecen encuadernados en pergamino, con una botonadura de cuerdas para abrochar. En el lomo, en ocasiones, dos o tres remaches de cuero sujetos con fibras entrecruzadas. En las hojas de guardas suelen utilizarse papel procedente de documentos o libros impresos y, en pocas ocasiones, pergamino. El tamaño es variado, aunque de modo general puede estimarse en unas dimensiones de $200 \times 300 \mathrm{~mm}$. Los legajos, por su parte, son atados de documentos protegidos por tapas de cartón, también de tamaño variable, predominando los de $210 \times 310 \mathrm{~mm}$.

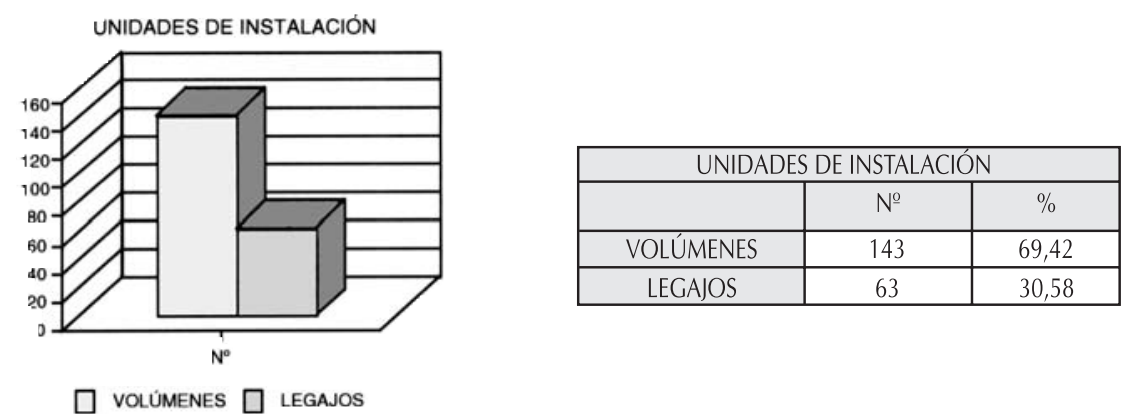

Figura 2

La mayor concentración de legajos la hallamos en los últimos 56 unidades de instalación. Es en esta área donde encontramos abundante documentación muy repetida de menor importancia histórica y archivística por encontrarse ya recogida en otros espacios del archivo y la biblioteca. Este motivo ocasiona que su conservación no sea tan necesaria por lo que comúnmente no se encuadernan, permaneciendo atados los documentos mediante balduques o hiladillos, no con poca frecuencia sin ninguna tapa de cartón que les proteja. 
3. El número de agrupaciones documentales es de 4.602, lo que supone una media de 22,34 documentos por unidad de instalación. La mayor concentración documental la encontramos en las 50 primeras unidades de instalación, decayendo constantemente hasta el final de la colección.

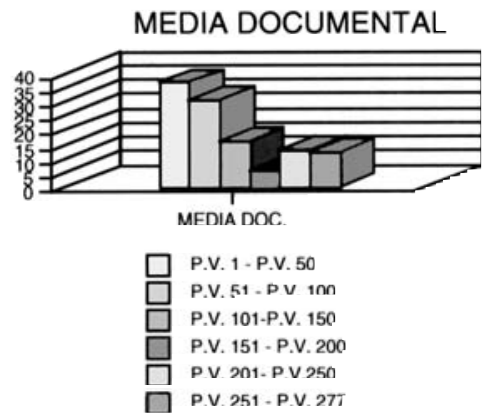

\begin{tabular}{|c|c|c|c|}
\hline \multicolumn{4}{|c|}{ MEDIA DOCUMENTAL POR P.V. } \\
\hline & $\begin{array}{c}\text { № } \\
\text { DE } \\
\text { P.V. }\end{array}$ & № DE DOCS. & $\begin{array}{c}\text { MEDIA } \\
\text { DOC. }\end{array}$ \\
\hline P.V. 1 - P.V. 50 & 50 & 1809 & 36,18 \\
\hline P.V. 51 - P.V. 100 & 50 & 1514 & 30,28 \\
\hline P.V. 101 - P.V. 150 & 50 & 795 & 15,9 \\
\hline P.V. 151 - P.V. 200 & 28 & 142 & 5,07 \\
\hline P.V. 201 - P.V. 250 & 14 & 179 & 12,78 \\
\hline P.V. 251 - P.V. 277 & 14 & 163 & 11,64 \\
\hline
\end{tabular}

Figura 3

4. En lo concerniente al análisis de los documentos por su condicion de ser manuscritos o impresos, debemos decir en primer lugar que en 171 unidades de instalación predominan los documentos impresos por 33 en que lo hacen los documentos manuscrito. Hay 2 en que hay igual número de manuscritos que de impresos.

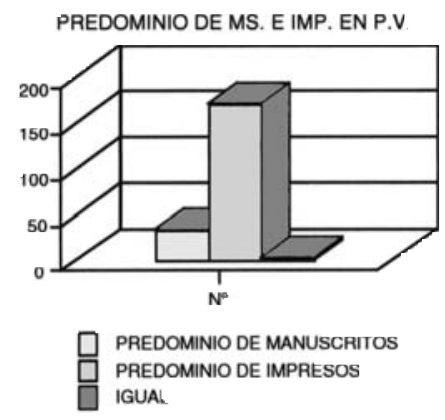

\begin{tabular}{|l|c|c|}
\hline \multicolumn{3}{|c|}{$\begin{array}{c}\text { PREDOMINIO DE MS. E IMP. } \\
\text { EN PAPELES VARIOS }\end{array}$} \\
\hline & № & $\%$ \\
\hline PREDOMINIO DE MS. & 33 & 16,02 \\
\hline PREDOMINIO DE IMP. & 171 & 83 \\
\hline IGUAL & 2 & 0,98 \\
\hline TOTAL & 206 & 100 \\
\hline
\end{tabular}

Figura 4

En relación con esta característica, se da un predominio de documentos impresos $(63,34 \%)$ frente a manuscritos $(36,66 \%)$. No obstante encontraremos una cifra considerable de documentos manuscritos, hasta tal punto que en las cincuenta primeras unidades de instalación hay más documentos manuscritos que impresos. 


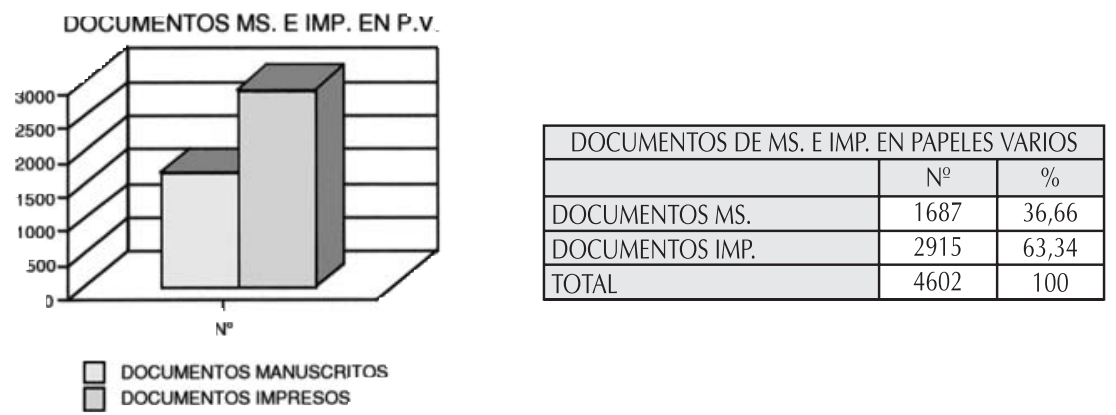

Figura 5

Por su parte, la media de los documentos manuscritos por P.V. es de 8,19 documentos. La mayoría de las agrupacionjes documentales manuscritas las encontramos en las 102 primeras unidades de instalación, de tal forma que en este P.V. ya nos situamos en el $95,69 \%$ del total de los documentos manuscritos.

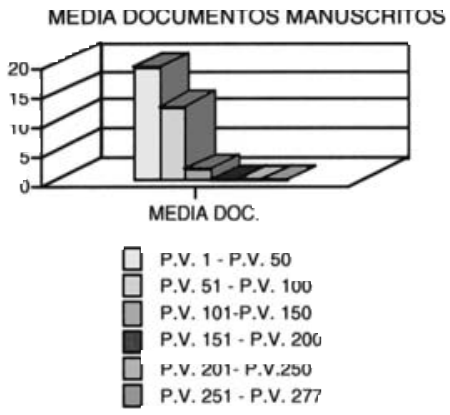

\begin{tabular}{|c|c|c|c|}
\hline \multicolumn{4}{|c|}{ MEDIA DOCUMENTAL DE MANUSCRITOS POR P.V. } \\
\hline & $\begin{array}{c}\text { № DE } \\
\text { P.V. }\end{array}$ & $\begin{array}{c}\text { № DE } \\
\text { DOCS. }\end{array}$ & $\begin{array}{c}\text { MEDIA } \\
\text { DOC. }\end{array}$ \\
\hline P.V. 1 - P.V. 50 & 50 & 969 & 19,38 \\
\hline P.V. 51 - P.V. 100 & 50 & 630 & 12,6 \\
\hline P.V. 101 - P.V. 150 & 50 & 86 & 1,72 \\
\hline P.V. 151 - P.V. 200 & 28 & 1 & 0,03 \\
\hline P.V. 201 - P.V. 250 & 14 & 1 & 0,07 \\
\hline P.V. 251 - P.V. 277 & 14 & 1 & 0,07 \\
\hline
\end{tabular}

Figura 6

En este sentido, una de las características es la gran desigualdad entre unos Papeles Varios y otros en lo que respecta al número de documentos manuscritos: mientras unos pocos reúnen prácticamente la totalidad de los documentos manuscritos, la mayoría no contiene ninguno, o uno o dos. ${ }^{23}$

Por otra parte, los documentos manuscritos hallados están relacionados con unas temáticas concretas: papeles vinculados a múltiples aspectos de la Compañía de Jesús y Dominicos, memoriales de pleitos, conflictos jurisdiccionales por diferentes motivos y causas, consultas y respuestas sobre diferentes temas, correspondencia polifacética de diferentes personajes y heterogéneos docu-

23. Si advertimos los datos generales referidos al número de documentos y los datos referentes a los documentos manuscritos, nos daremos cuenta de que son los mismos P.V. los que contienen mayor número de documentos en general y los que contienen mayor número de documentos manuscritos. 
mentos concernientes a multiples aspectos de personajes vinculados a la Universidad de Salamanca.

En lo que respecta a los documentos impresos, la media es de 14,15 documentos por unidad de instalación. En este sentido, en toda la colección contamos con una media bastante uniforme, a excepción del descenso producido entre el P.V. 151 y P.V.200, debido en parte al contabilizar como sólo un documento impreso los que aparecen abundantemente repetidos.

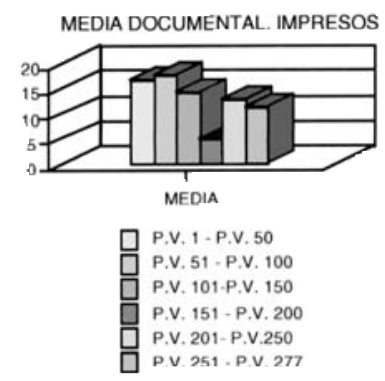

\begin{tabular}{|c|c|c|c|}
\hline \multicolumn{4}{|c|}{ MEDIA DOCUMENTAL DE IMPRESOS POR P.V. } \\
\hline & $\begin{array}{c}\text { № DE } \\
\text { P.V. }\end{array}$ & $\begin{array}{c}\text { № DE } \\
\text { DOCS. }\end{array}$ & $\begin{array}{c}\text { MEDIA } \\
\text { DOC. }\end{array}$ \\
\hline P.V. 1 - P.V. 50 & 50 & 840 & 16,8 \\
\hline P.V. 51 - P.V. 100 & 50 & 881 & 17,62 \\
\hline P.V. 101 - P.V. 150 & 50 & 710 & 14,2 \\
\hline P.V. 151 - P.V. 200 & 28 & 146 & 5,21 \\
\hline P.V. 201 - P.V. 250 & 14 & 178 & 12,71 \\
\hline P.V. 251 - P.V. 277 & 14 & 160 & 11,43 \\
\hline
\end{tabular}

Figura 7

Tal y como ocurría con los documentos manuscritos, existe una relación directa entre el contenido y la tipología del documento y su presentación impresa. En este sentido, abundan mayoritariamente sermones, honras fúnebres, oraciones laudatorias, memoriales varios, relaciones de fiestas, narraciones, abundante, documentación cortesana y documentación pontificia.

5. En lo referente al análisis cronológico, la colección de Papeles Varios reúne documentación desde el siglo XVI hasta el siglo XIX. En este orden de cosas, se caracteriza por un predominio de los documentos fechados en el s. XVIII $(61,37 \%)$, seguido de los del s. XVII $(31,15 \%)$. Al margen, encontramos documentos de los siglos XIX (4,05\%) y XVI (3,43\%).

Si extraemos las fechas predominantes por siglos y unidad de instalación nos dará como resultado la siguiente tabla y el correspondiente gráfico:

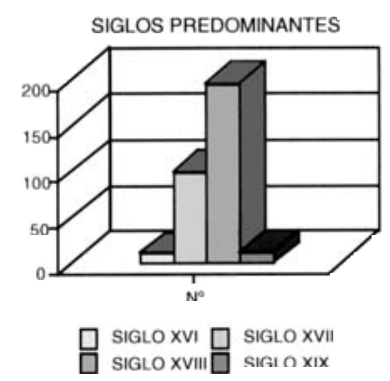

\begin{tabular}{|c|c|c|c|}
\hline \multicolumn{4}{|c|}{ SIGLOS PREDOMINANTES POR UNIDAD } \\
DE INSTALACIÓN ${ }^{24}$ \\
\hline SIGLOS & № & $\%$ & $\%$ ACUMULADO \\
\hline S. XVI & 11 & 3,43 & 3,43 \\
\hline S. XVII & 100 & 31,15 & 34,58 \\
\hline S. XVIII & 197 & 61,37 & 95,95 \\
\hline S. XIX & 13 & 4,05 & 100 \\
\hline TOTAL & 321 & 100 & 100 \\
\hline
\end{tabular}

Figura 8 
Por consiguiente, el centro neurálgico cronológico lo encontramos en la primera mitad del s. XVIII, aminorándose la cantidad de documentos en la medida en que nos alejamos de este período. Estos datos se confirman si extraemos las fechas predominantes de cincuenta en cincuenta años:

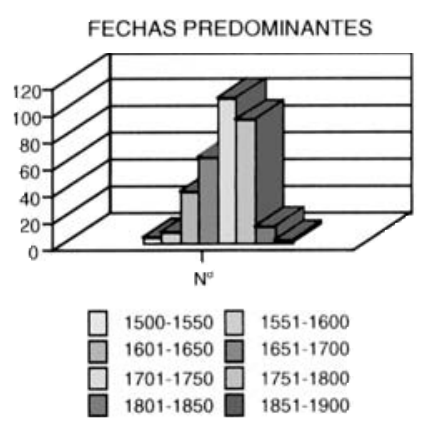

\begin{tabular}{|c|c|c|c|}
\hline \multicolumn{5}{|c|}{$\begin{array}{c}\text { FECHAS PREDOMINANTES POR UNIDAD } \\
\text { DE INSTALACIÓN }\end{array}$} \\
\hline FECHAS & № & $\%$ & $\%$ ACUMULADO \\
\hline $1500-1550$ & 4 & 1,27 & 1,27 \\
\hline $1551-1600$ & 8 & 2,45 & 3,72 \\
\hline $1601-1650$ & 38 & 11,65 & 15,37 \\
\hline $1651-1700$ & 64 & 19,63 & 35 \\
\hline $1701-1750$ & 107 & 32,81 & 67,81 \\
\hline $1751-1800$ & 92 & 28,22 & 96,03 \\
\hline $1801-1850$ & 11 & 3,36 & 99,39 \\
\hline $1851-1900$ & 2 & 0,61 & 100 \\
\hline TOTAL & 326 & 100 & 100 \\
\hline
\end{tabular}

Figura 9

Por contenidos, entre la documentación perteneciente al s. XVIII abundan sermones, oraciones fúnebres, oraciones laudatorias, manifiestos, cédulas y pragmáticas reales, reglamentos varios, copias de bulas y breves y documentación varia vinculada a los Dominicos, Jesuitas y la Universidad de Salamanca. Perteneciente al s. XVII sobresalen los memoriales de pleitos, asuntos políticos -como el relacionado con la Restauracao portuguesa-, abundantes dictámenes religiosos, consultas jurídicas y eclesiásticas y otra documentación varia vinculada con múltiples asuntos de la Orden de los Predicadores, la Compañía de Jesús y la institución universitaria salmantina. Al s. XIX pertenece esencialmente el fondo procedente de Lorenzo Velasco, algunos reglamentos y ordenanzas y cartas pastorales. Por último, al s. XVI, pleitos y conflictos jurisidiccionales varios, copias de documentos medievales de diferente contenido y temática, acuerdos y concordias y otras piezas documentales vinculados con cabildos y obispados.

24. Cuando la diferencia en las fechas predominantes de un siglo respecto a otro sea menor a $+/-2$ apuntamos como fechas predominantes ambos siglos.

25. Al igual que antes, cuando la diferencia no sea mayor a $+/-2$ apuntaremos como fechas predominantes ambas. 
6. En lo que respecta al análisis topográfico o lugares en los que se fechan y otorgan los documentos, estamos en condiciones de afirmar que aproximadamente un $75 \%$ de la documentación ubicada en la colección de Papeles Varios refieren en su data tópica lugares pertenecientes a la España actual. ${ }^{26}$ De dicha cifra, destacan sobremanera dos lugares por razones lógicas: Madrid, cabeza de la Monarquía y centro cultural, impresor y editorial, y Salamanca, sitio de la ubicación y metrópolis universitaria. Además, destacan a gran distancia otros centros urbanos: Barcelona, Córdoba, Cuenca, Granada, Jaén, León, Pamplona, Segovia, Sevilla, Toledo, Valencia, Valladolid, Zamora o Zaragoza.

De los lugares "extranjeros" predomina fundamentalmente Roma, con más de la mitad de las referencias que conocemos, debido fundamentalmente a la documentación pontificia proveniente de la Corte Romana y sus vinculaciones con la Órdenes religiosas y la Universidad de Salamanca. En este orden de cosas, nuestros papeles destacan por la presencia de documentación datados en múltiples lugares de fuera de España, lo que define a la colección como sitio cosmopolita, universal y alejada del localismo provinciano. La presencia de documentos datados y otorgados en Bayona, Bolonia, Bruselas, Coimbra, Colonia, Filipinas, La Habana, Lisboa, Londres, Lovaina, Macao, Milán, Nápoles, París, Pekín, Praga, Turín, Utrech, Varsovia, Venecia, o Viena responde no sólo a que la Salamanca clásica se convierte en estos siglos en "la más afamada e influyente de la Monarquía Hispánica, estereotipo de prestigio e institución de educación superior sobresaliente con grados reconocidos, pluriforme en materias de enseñanzas, con las cátedras mejor pagadas y la menos regional en sus contingentes de alumnado", ${ }^{27}$ sino también a las importantes relaciones culturales de las Órdenes religiosas, en especial Jesuitas y Dominicos, vinculados institucionalmente a la salmantina. En definitiva, mucho del cosmopolitismo que caracteriza a la colección de Papeles Varios se debe al Convento de San Esteban de los Dominicos y al Real Colegio del Espíritu Santo de la Compañía de Jesús.

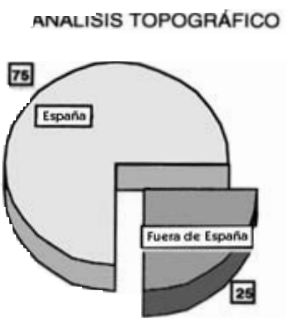

Figura 10

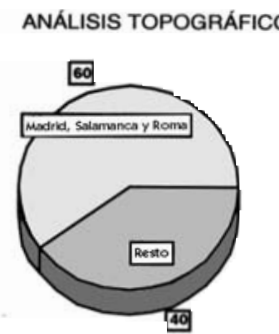

Figura 11

26. No la Monarquía Hispánica, que desde el s. XVI hasta el s. XIX fue perdiendo territorio paulatinamente.

27. Cfr. RODRÍGUEZ-SAN PEDRO BEZARES, L.E. "La Universidad de Salamanca: evolución y declive de un modelo clásico", en Stvdia Historica. Historia Moderna, 1991, IX, p. 13. 
Así pues, las principales zonas topográficas son Madrid, Salamanca y Roma, seguidas de lejos por Lisboa, Sevilla, Valladolid y Granada. Si entre las tres primeras, y como prueba de concentración topográfica, suman cerca de un $60 \%$ del total de los documentos reconocidos, el otro $40 \%$ se caracteriza por una destacada dispersión topográfica.

7. En lo referente al análisis idiomático, predominio de los documentos en castellano, seguido del latín. Marginalmente encontramos documentos en portugués, francés, italiano, catalán, griego e incluso uno en chino. Mientras que los documentos en castellano pueden representar aproximadamente un $75 \%$ del total y refieren documentos de múltiples tiplogías y diversos contenidos, los latinos se vinculan prefetentemente a contenidos eclesiásticos.

8. La colección de Papeles varios se caracteriza por tener heterogéneas y múltiples procedencias documentales.

No es necesario volver a reincidir aquí en la importancia especial que merece el principio de procedencia o respect des fonds en materia archivística. Sin embargo, su análisis entraña una enorme dificultad en colecciones documentales como la que estamos estudiando. El que presenten infinidad de tipologías documentales, el que procedan de múltiples y diferentes funciones, actividades y fines, y su corriente desclasificación y desordenación justifica que los archivos conciban una sección facticia para aquellos documentos que no se encuadran en ninguna de las otras secciones del archivo, esto es, que han sido tratados como inclasificables, justamente en la mayoría de las ocasiones por la imposibilidad de averiguar su procedencia de modo fidedigno.

Vertidas estas aclaraciones, hemos demostrado que la procedencia mayoritaria es la conventual. De las 206 unidades de instalación, en 133 (64,56\%) tienen procedencia conventual, por $20(9,71 \%)$ que no la tienen. De las 53 restantes $(25,73 \%)$ no tenemos datos consistentes, pero casi nos atreveríamos a afirmar que repiten prácticamente estos porcentajes.

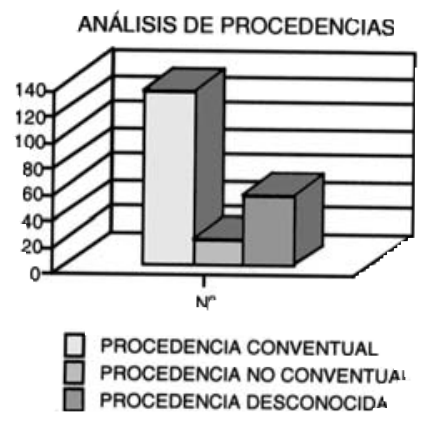

\begin{tabular}{|l|c|c|c|}
\hline \multicolumn{4}{|c|}{ ANÁLISIS DE PROCEDENCIAS } \\
\hline & № & $\%$ & $\%$ ACUMULADO \\
\hline PROC. CONVENTUAL & 133 & 64,56 & 64,56 \\
\hline PROC. NO CONVENTUAL & 20 & 9,71 & 74,27 \\
\hline PROC. DESCONOCIDA & 53 & 25,73 & 100 \\
\hline TOTAL & 206 & 100 & 100 \\
\hline
\end{tabular}

Figura 12 
En lo concerniente a la procedencia conventual cabría decir que predominan de forma mayoritaria la jesuítica $(58,01 \%)$ y la dominica $(38,93 \%)$. Las unidades de instalación provenientes del Colegio Real del Espíritu Santo de Salamanca pasaron a formar parte del Archivo Universitario en la segunda mitad del s. XVIII debido a la expulsión de la Compañía de Jesús de España en 1767. Destaca de entre todos el fondo personal del P. Pedro Abarca (S.I.), o las obras de Luis de Losada (S.I.) Por su parte, las procedentes del Convento de San Esteban de Salamanca de la Orden de Predicadores pasaron a formar parte del Archivo Universitario en el s. XIX debido a la exclaustración de la órdenes regulares. Destaca el fondo del P. José Barrio (O.P.).

Además, también contamos con volúmenes o legajos procedentes de otras Órdenes religiosas: Franciscanos (1,54\%), Cistercienses $(0,76 \%)$, o Agustinos Calzados $(0,76 \%)$.

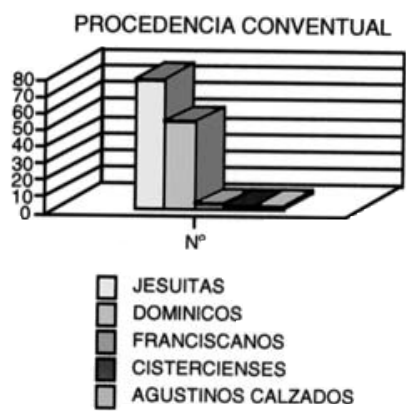

\begin{tabular}{|l|c|c|c|}
\hline \multicolumn{4}{|c|}{ PRODENCIA CONVENTUAL } \\
\hline & № & $\%$ & $\%$ ACUMULADO \\
\hline JESUITAS & 76 & 58,01 & 58,01 \\
\hline DOMINICOS & 51 & 38,93 & 96,94 \\
\hline FRANCISCANOS & 2 & 1,54 & 98,48 \\
\hline CISTERCIENSES & 1 & 0,76 & 99,24 \\
\hline $\begin{array}{l}\text { AGUSTINOS } \\
\text { CALZADOS }\end{array}$ & 1 & 0,76 & 100 \\
\hline TOTAL & 131 & 100 & 100 \\
\hline
\end{tabular}

Figura 13

En lo que respecta a las procedencias no conventuales, hemos de destacar el papel destacado de los fondos colegiales, esto es, Colegios Mayores seculares vinculados a la Universidad de Salamanca. Sobresale el Colegio Mayor de Cuenca $(60 \%)$, que fundamentalmente se determina en memoriales de pleitos, conflictos jurisdiccionales varios localizados en las diócesis de Jaén, Cuenca y Guadalajara, y sermones y oraciones fúnebres y panegíricas varias pronunciados por algún colegial o en su honor. Del mismo modo, hemos localizado documentación procedente del Colegio Mayor de Santiago el Zebedeo (15\%), aunque en menor medida. Por otra parte, merece especial mención el fondo procedente del archivo personal de Lorenzo Velasco González (20\%), personaje local influyente, con documentación de finales del s. XVIII y principio del s. XIX. Predominan las instrucciones y órdenes para el gobierno de las aduanas del Reino de Galicia, abundantes documentos de marcado carácter económico del partido de Alba de Tormes y algunos cuadernillos manuscritos sobre noticias de la provincia de Salamanca. Por último, también hay algunos documentos procedentes del Obispado de Salamanca (5\%). 
No debe sorprendernos la ausencia de documentos procedentes del Archivo del Secretario de la Universidad de Salamanca. La colección de Papeles Varios no surge por las actividades, funciones y fines del aparato administrativo de la Universidad de Salamanca, lo cual no significa que no sea documentación universitaria -por cuanto procede de instituciones vinculadas a la institución salmantina-, o que no trate o concierna a temática universitaria.

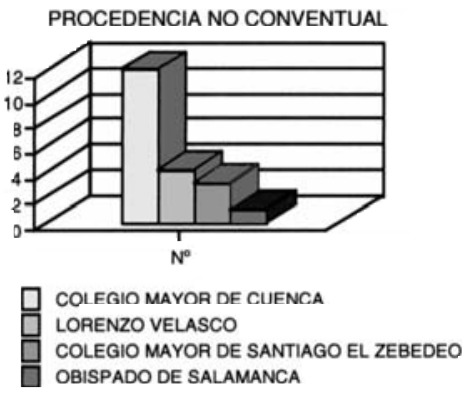

\begin{tabular}{|l|c|c|c|}
\hline \multicolumn{4}{|c|}{ PROCEDENCIA NO CONVENTUAL } \\
\hline & № & $\%$ & $\%$ Acumulado \\
\hline CGO. MAYOR DE CUENCA & 12 & 60 & 60 \\
\hline LORENZO VELASCO & 4 & 20 & 80 \\
\hline CGO. MAYOR SANTCO. EL ZEBEDEO & 3 & 15 & 95 \\
\hline OBISPADO DE SALAMANCA & 1 & 5 & 100 \\
\hline TOTAL & 20 & 100 & 100 \\
\hline
\end{tabular}

Figura 14

9. Múltiples y diversas tipologías documentales, esto es, los documentos derivan de heterogéneas actividades y competencias. ${ }^{27}$ Contamos con documentación constitutiva -documentos que por imperativo legal constituyen un derecho desde el mismo momento de su realización-, probatoria -recogen la existencia de un hecho o un derecho- e informativa -dice e informa, pero no constituye ni prueba-. De este modo, están presentes, entre otros, Reales Cédulas, peticiones, memoriales, instancias, informes, cartas, certificaciones, reglamentos, títulos de propiedad, escrituras de obligación, cláusulas de testamento, recibos de arbitrios, inventario de bienes, concordias, acuerdos, bulas, breves, capítulos y constituciones, ventas, donaciones, ordenanzas y fueros, juramentos, etc.

10. Del mismo modo, desde el punto de vista de la tradición documental, es decir, por la situación de un documento entre el que fue querido y redactado por su autor la primera vez de un modo definitivo, por un lado, y el que nos ha llegado a nosotros, por otro, encontramos minutas -documento preparatorio,

28. Quisiera Ilamar la atención aquí sobre la dificultad que plantea al estudioso la ausencia de estudios sobre tipología diplomática para la Edad Moderna. La Ilamada de la II Conferencia Europea de Archivos, celebrada en la Universidad de Michigan entre el 9-13 de Mayo de 1989, sigue siendo válida hoy. Entre las conclusiones se recomendó lo siguiente: "que el desarrollo de la Diplomática sea incentivado por investigaciones sobre la tipología de los archivos". (Vid. CORTÉS ALONSO, V. La escritura y lo escrito. Manual de Paleografía y Diplomática de España y América en los siglos XVI y XVII, Madrid, 1986). 
provisional y previo al ejemplar original-, originales -con toda la plenitud de formas y cautelas del autor- y copias - presenta un documento tal y como resulta de otro-. Del mismo modo, hemos localizado algunas categorías intermedias (inserciones, confirmaciones, renovaciones, etc.)

11. Ahora bien, ¿qué provecho tiene esta colección para la realización de investigaciones históricas? ¿Cuáles de relieve podrían realizarse mediante la utilización de esta documentación?

Para su estudio hemos establecido tres categorías temáticas. Una primera que podríamos denominar de temas o contenidos históricos específicos o naturales. Esto es, documentos que revelan abundante información histórica sobre copiosos aspectos vinculados a la Orden de la Compañía de Jesús, la Orden de los Predicadores y la Universidad de Salamanca. Por consiguiente, aquellos temas que tienen relación directa con la procedencia prioritaria de la documentación -Jesuitas y Dominicos- y su destino -Universidad de Salamanca. Una segunda que denominaríamos como temas o contenidos prioritarios o preferentes. En este sentido, consideramos que basándonos en la documentación existente, podríamos realizar, al margen de otros muchos, seis trabajos de investigación histórica de especial relieve: un estudio sobre parenética basado en los sermones y oraciones fúnebres y panegíricas del s. XVIII, un análisis de la historiografía de la Secesión de Portugal, un estudio de la sátira y sus vertientes políticas, sociales y religiosas, una investigación sobre determinados aspectos económicos y sociales de la ciudad de Salamanca y su partido judicial en el s. XIX, un análisis de la fiesta en los siglos XVII y XVIII como manifestación de la religiosidad popular, $y$ un estudio sobre Colegios y otras instituciones universitarias.Y, por último, una tercera categoría, de menor envergadura, pero sin por ello desmerecer su relevancia, y que correspondería a otros temas. Hacemos, por consiguiente, mención a temas de menor relieve, pero que también debieran ser analizados desde un punto de vista histórico: determinados asuntos internacionales de carácter fundamentalmente político, los conflictos jurídicos y pleitos por causas de derecho privado, la constante arbitrista con sus variantes, y multitud de asuntos que nos servirían para la realización de lo que se ha dado en llamar historia de las mentalidades y que se viene manifestando como una preocupación constante por comprender mejor el paso a la modernidad.

Empecemos, pues, por analizar, aunque sea de manera escueta, los temas $o$ contenidos históricos específicos o naturales, esto es, documentación que revela abundante información histórica sobre copiosos aspectos vinculados a Jesuitas, Dominicos y la Universidad de Salamanca.

Como viene quedando de manifiesto, el fondo de Papeles Varios es fundamentalmente de procedencia conventual, y en este sentido será de formidable importancia para el historiador especialista en Órdenes Religiosas, que sabrá en todo momento explotar como nadie la documentación aquí presente. 
El tema Jesuítico es un dominio constante en los Papeles Varios. Pueden ser analizados de forma exhaustiva temas tales como lo relativo a su expulsión de Portugal, Francia y España, las relaciones de la Orden con los diversos pontificados, sus conflictos religiosos, la controversia sobre la Inmaculada Concepción, las posturas frente a diversas beatificaciones y canonizaciones como la de Juan de Palafox y Mendoza, sus puestas en escena en determinadas misiones, el denominado conflicto de ritos en China, sus relaciones con los Dominicos y con la Universidad de Salamanca e información sobre colegios como el de Santiago de Compostela, el de Tudela, el de San Hermenegildo de Sevilla, o el Seminario de Murcia. Encontramos relaciones del asunto jesuítico con múltiples sátiras, sus relaciones con los judíos o asuntos internacionales en los que se encuentran implicados. Al margen, obras de autores como las de Luis de Losada y Prada entre otros. Destaca el fondo personal de Pedro Abarca: cartas relacionadas con sus obras y disquisiciones históricas, documentación sobre los sucesos de Cataluña de 1684, sobre la posible invasión de Pamplona por los franceses y múltiples aspectos relacionados con la Universidad de Salamanca. En definitiva, una auténtica cantera para especialistas en los asuntos de la Compañía.

Con el tema Dominico sucede algo similar. Hay abundante documentación que toca de una $\mathrm{u}$ otra forma asuntos relacionados con la Orden de los Predicadores: desde los numerosos asuntos internos - como las materias tocantes al gobierno, elecciones y nombramientos de priores y provinciales o información sobre los capítulos generales y provinciales- pasando por las imbricaciones de sus Colegios con el resto de los Colegios Mayores y Menores, hasta los abundantes dictámenes eclesiásticos, consultas y respuestas de alguno de sus frailes. Hay abundante documen tación sobre el Convento de San Ildefonso el Real de Toro y el Monasterio de San Pablo de Valladolid. Además, es abrumadora la documentación sobre el Colegio Dominico de San Gregorio de Valladolid. Destaca la presencia del fondo personal de José Barrio: abundante correspondencia, aprobaciones y comentarios a manifiestos y escritos de otros autores, documentación sobre diversas elecciones de cargos internos, etc. Si tuviésemos que hacer distingos frente a la temática jesuítica, diríamos que los Dominicos presentan un contenido menos internacional -salvando la cuestión misional- y más local, esto es, con una abrumadora documentación relacionada directamente con el Convento de San Esteban de Salamanca.

En lo concerniente a la temática que hace referencia a la Universidad de Salamanca, sucede lo mismo que con los temas anteriormente expuestos. La institución universitaria encuadra su afán intelectual y teórico en unas circunstancias concretas y en un marco social de referencias. En este sentido, el fondo es útil para "el estudio de la inserción histórica de la Universidad, el análisis de sus conexiones con el poder, la trayectoria económica, los grupos sociales, los intereses contrapuestos, la ideología, creencias, actitudes y sensibilidades de cada momento'22.

29. Cfr. RODRíGUEZ-SAN PEDRO BEZARES, L.E. "La Universidad de Salamanca...", op. cit., p. 9. 
De manera que la temática universitaria toca tangencialmente otros muchos contenidos. Son analizables diversas y variadas cuestiones hacendísticas de la Universidad, como lo referente a las cuentas generales y las Juntas especiales, los cargos de la Universidad (tercias, arriendo de casas, censos y multas)y los descargos (salario de cátedras y oficiales, subsidio y excusado, carnicerías y alhóndigas, etc.); por otro lado, son dignos de investigar los documentos que hacen referencia a la organización jerárquica y administrativa: relaciones con los poderes civiles y las autoridades religiosas, Constituciones, Estatutos y Privilegios, poderes y encargos de las distintas autoridades académicas (rector, maestrescuela, primicerio, diputados, claustros plenos y conservadores). También hay documentación relevante para el análisis del régimen docente y la atmósfera intelectual: interrogantes y conflictos sobre los Planes de Estudios, provisión y alternativa de cátedras, participación del claustro universitario en la provisión de cátedras y concesión de partidos, método de enseñanza, tensiones y conflictos frente a los Colegios Mayores y Militares. Por último, es notoria la documentación que hace mención a las vinculaciones de la Universidad de Salamanca con Jesuitas y Dominicos en múltiples y variados aspectos, y curiosa la que bien pudiera servir para el estudio de los grupos profesionales de la Universidad y la vida estudiantil cotidiana.

En segundo lugar, contamos con lo que hemos dado en llamar temas o contenidos prioritarios o preferentes.

En este sentido, sería muy positivo la realización de una parenética basada en los abundantes sermones y oraciones fúnebres y panegíricas. Es esta una documentación que abunda sobremanera. Son pronunciados por diversos personajes, la mayoría de ellos vinculados directa o indirectamente con la Universidad de Salamanca, y son de enorme importancia para el análisis de acontecimientos históricos e incluso políticos. En este sentido, sería digno la realización de un estudio del profesorado universitario a través de esta documentación.

La Restauraçao portuguesa y la Secesión de Portugal en 1640 también es un tema preferente.Contamos con tres tipos de documentos que tocan directamente esta temática: un primer grupo denominado crónicas coetáneas. Dichas crónicas revelan una gran información sobre los hechos del movimiento portugués de 1640, a lo que se añade un importante componente interpretativo; destacan en este mismo sentido los diarios personales y gacetas referidos al período "revolucionario". Un segundo grupo, denominado literatura panfletaria de combate; se puede observar desde aquí el alto grado de importancia que tiene la publicística como medio de comunicación escrita, típicamente barroca. Género de literatura política susceptible, a su vez, de reagrupar muchas clases de escritos, de naturaleza y carácter diferente (manifiestos, alegatos, pasquines, etc.) que tienen en común el ser relativamente breves para los criterios del s. $\mathrm{XVII}$ y responder siempre a una coyuntura muy precisa. $\mathrm{Y}$ un tercer grupo, que 
podríamos calificar de obras indirectas, que aportan datos útiles para el historiador, sin interpretación específica del "periodo revolucionario". ${ }^{30}$

Otra tema digno de ser estudiado es la sátira política y religiosa como composición poética cuyo objeto es censurar acremente o poner en ridículo a personas o cosas mediante un discurso agudo, picante y mordaz; y es fundamentalmente política y religiosa porque son estos ámbitos los que impregnan todo en la vida del Antiguo Régimen. La sátira, pues, como perspectiva desde donde puede analizarse el momento histórico con todas sus implicaciones. Décimas satíricas a la caída del Marqués de la Ensenada, coplas a la caída del P. Francisco Rábago, confesor de Fernando VI, décimas a José I y al Marqués de Pombal, pasquines y coplas contra el concordato de 1753, sátiras sobre la exaltación al trono de Fernando VI o múltiples sonetos al gobierno de la Monarquía están presentes.

También encontramos documentación con la que es posible investigar en temas de historia local, en concreto para la ciudad de Salamanca y su entorno. En este sentido, es abundante la documentación de carácter económico del partido de Salamanca de los años finales del s. XVIII y principios del XIX. Contamos con las cuentas generales del ramo de propios y arbitrios del ayuntamiento de Salamanca de 1844-48, las cuentas que pagaban las Iglesias en el partido de Alba de Tormes desde 1796 hasta 1836, la administración de D. Félix Golfín Calderón, Conde de Oliva y Marqués de Valdeiglesias, las continuas quejas contra los intendentes corregidores, o los conflictos de frontera con Portugal tanto en la crisis de mediados del s. XVII como en la Guerra de Sucesión. Para este tema es fundamental el fondo personal de Lorenzo Velasco.

La temática festiva está presente bajo abundantes discursos literarios -que son conocidos bajo múltiples denominaciones, libro de honras, de fiestas, libreto o relaciones- donde se presentan relaciones de hechos que son una memoria minuciosa, pormenorizada, Ilena de acontecimientos efímeros. A través de los textos observaremos "cómo la arquitectura y el urbanismo de las distintas ciudades -también de Salamanca-, el discurso y la fiesta se anudan en su calidad instrumental, prestas a ser manipuladas desde diversas instancias" -como por ejemplo la Universidad, la ciudad o la Iglesia ${ }^{31}$. Además, hemos de tener en cuenta que la intensa y ferviente religiosidad del pueblo español tenía, naturalmente, que traducirse en numerosas, variadas y brillantísimas fiestas religiosas, ya en las usuales ocasiones de precepto, ya en los casos de índole excepcional que relacionados con la religión surgían constantemente. En este sentido, las fechas memorables de la dinastía o la política, lo mismo nacionales que regio-

30. Para todo ello, vid. mi artículo: "Historiografía de la Secesión de Portugal en los fondos documentales Manuscritos y Papeles varios de la Biblioteca Universitaria de Salamanca. Una primera aproximación al tema" en Op. Cit.

31. Cfr. MONTANER LÓPEZ, E. "Exequias reales y pompa funeral (Salamanca 1600-1621)". En: BONILLA HERNÁNDEZ, J.A. (Coord.). Salamanca y su proyección en el mundo. Estudios históricos en honor de D. Florencio Marcos. Salamanca, 1992, p. 534. 
nales, se celebraban siempre con pompa eclesiástica, y no faltaba jamás la solemnidad religiosa, fuera por el nacimiento de un príncipe heredero, fuera por la celebración de la fiesta onomástica de los reyes, o por la visita del soberano a las capitales de provincia, fuera, en fin, por la comunicación de faustas noticias o de triunfos conseguidos en los campos de batalla. De todo ello, tenemos noticias entre nuestros documentos.

Por último, es digno de reseñarse la documentación vinculada a Colegios y universidades del resto de la Monarquía hispánica. En lo que a los Colegios se refiere son frecuentes los asuntos relativos a las discordias entre los Mayores y los Militares o las reformas de los Colegios Mayores. Es predominante lo concerniente al Mayor de San Bartolomé y al Militar del rey. Respecto a Universidades, contamos con documentación sobre la Universidad de Alcalá, Ávila, Baeza, Lérida, Santiago de Compostela, Santo Tomás de Quito, Sevilla, Sigüenza y Valencia.

Y en tercer y último lugar, hacemos mención a otros temas de importancia relevante, dignos de ser analizados por reunir documentación para ello entre los legajos que conforman nuestra colección de Papeles Varios:

En primer lugar, los asuntos de marcado carácter internacional que dan aires de cosmopolitismo a nuestra sección facticia. La paz con Francia, la pugna religiosa, el frente musulmán, el frente norte, la pugna por el dominio de Occidente (Portugal) y el régimen colonial podrían ser los grandes apartados. Asuntos vinculados a los turcos, a Francia, a diversas guerras con Portugal, a Inglaterra y Escocia, o con las colonias en América y en Oceanía son tratados aquí. Como análisis histórico sería viable la realización de un catálogo de documentos clasificados temáticamente por las zonas geográficas a las que se hace referencia, ya sea la proclamación del Rey de Escocia Jacobo VII, las noticias de la corte inglesa, la cuestión sucesoria en Polonia en 1733 o los asuntos sobre el Nápoles de Carlos VI.

En segundo lugar, los conflictos jurídicos de distinta naturaleza y pleitos. Son abundantes los conflictos "de familia y sucesiones" donde los conceptos de capítulo matrimonial, dote, fideicomiso, filiación, heredamiento, legado, legítima, mayorazgo, mejora y testamento tienen especial significado. Sería necesario un estudio, que llevado a cabo por especialistas, descifrara y analizara los diferentes conflictos según su diversidad temática. A buen seguro, que de la diferente tipología que resultara podría extraerse como telón de fondo el análisis de los problemas capitales de la España de los Austrias.

Es Ilamativa la presencia en este fondo de Cédulas, Pragmáticas y otros tipos de documentación cortesana impresa. Resulta abundante la documentación de la etapa borbónica -Felipe V, Fernando VI y Carlos III: asuntos concernientes a la economía doméstica, a costumbres financieras, prohibiciones sociales, medidas sobre las finanzas estatales y los metales preciosos, sobre la condición social del campesinado, acerca de los marginados y los problemas del paupe- 
rismo, sobre el sistema educativo, sobre la industria textil, sobre los cultivos, la agricultura y la ganadería, los gitanos. En definitiva, a través de la documentación cortesana puede estudiarse la profundización de las reformas borbónicas.

Del mismo modo, es abundantísima la documentación pontificia. Dicha documentación está vinculada, en primer lugar, con Jesuitas y Dominicos, ya sea para encaminar las relaciones con el Pontificado o para justificar y percibir determinados privilegios; y en segundo lugar, con la Universidad de Salamanca, donde el Maestrescuela respondía directamente ante el Pontífice, frente al Claustro que lo hacía ante el Consejo de Castilla y el Monarca, estableciéndose así el denominado equilibrio de poderes. Hemos de constatar, por otra parte, la presencia, en ocasiones de manera asombrosamente repetitiva, de determinados Bulas y Breves, que debieron llegar a los conventos salmantinos para que desde allí se repartieran a otros muchos conventos de las Órdenes respectivas. Por último, cabe decir aquí, cómo desde la presente documentación podemos seguir los pasos que se siguieron y las actitudes que se secundaron con el Pontificado, ya sea desde la Compañía de Jesús, desde la Orden de los Predicadores o desde la Universidad de Salamanca. En este orden de cosas, son frecuentes los comentarios a la Bula "Praetiosus" y la "Unigenitus", junto con abundantes noticias sobre el cónclave de 1691 y la elección del Papa Inocencio XII.

Por otra parte, los Papeles Varios son una joya valiosísima para los aspectos de Religiosidad y Mentalidades. Es abundante la documentación que desvela los diversos tonos de la religiosidad de la España de los siglos XVII y XVIII fundamentalmente: exaltación de la fe, fervor religioso, propaganda católica, fundacio nes piadosas y devocionales, culto a la Virgen y a los santos, desviaciones del sentimiento religioso, frivolidad y ritualismo, chocarrerías e irreverencias en cosas de religión, festividades religiosas, abundancia de prodigios, taumaturgos y embaucadores, apariciones demoníacas, posesiones diabólicas, milagros, etc. quedan registrados en nuestra documentación. La mentalidad, pues, como inconsciente colectivo; colectivo, porque es común a toda una sociedad en un determinado momento; e inconsciente, porque difícilmente o en absoluto es percibido por los contemporáneos, ya sea porque forma parte de los datos inmutables de la naturaleza, ya sea porque son ideas recibidas y vagas, lugares comunes, códigos de decencia y de moral, conformismos o prohibiciones, etc. La mentalidad, por consiguiente, como un todo compuesto de cinco componentes: lo racional, lo emotivo, lo imaginario, lo inconsciente y la conducta. ${ }^{32}$ En nuestro caso, pues, identificación entre orden natural y orden sobrenatural. Destacan los asuntos concernientes a la devoción al Sagrado Corazón de Jesús, las controversias mariológicas sobre la Inmaculada Concepción, distintas relaciones de milagros y exorcismos, o documentación diversa sobre Hermandades y Cofradías.

32. Vid. BARROS, Carlos: "Historia de las mentalidades: posibilidades actuales" en Problemas Actuales de la Historia.: Terceras Jornadas de Estudios Históricos. Salamanca: Universidad de Salamanca, 1993. pp. 50-53. 
Por otro lado, la temática arbitrista es digna de ser analizada en los Papeles varios. Se refleja en nuestra documentación los difíciles problemas económicos planteados en el reinado de los Austrias. La política mercantilista, basada en la protección de la industria nacional mediante la prohibición de exportar materias primas y la de importar productos manufacturados, el objetivo de poblar el reino, la vuelta al pasado medieval y a los ejes que robustecieron el imperio español, o una reforma de hábitos y tendencias en el trabajo son algunos de los temas de nuestros documentos. El arbitrismo, pues, definirá la introspección colectiva, un esfuerzo de toda la sociedad por autoanalizarse críticamente para encontrar las verdaderas causas del declive español. En este sentido, encontraremos memoriales rigurosos y otros menos serios que simplemente pretenden hacer propuestas irracionales sin otro objeto que ocupar la ociosidad o lograr notoriedad en la Corte. ${ }^{33}$

Por último, están también presentes otros muchos contenidos relacionados con otras temáticas. Es el caso de la historia de las minorías -judíos, conversos, gitanos, esclavos, etc.- el tema inquisitorial -desde la denuncia al auto de fe y sus imbricaciones políticas y morales, pasando por censuras librarias-, los temas económicos -falsificación, acuñación y exportación de la moneda, medidas financieras y arbitristas, etc.- genealogías de familias y linajes, documentación relativa a otras ciudades -Madrid, Málaga, Pamplona, Santiago, Vitoria, Valencia, etc.- narraciones de catástrofes naturales -terremotos en Málaga de 1680, en Cuzco en 1650, en Manila hacia 1660, tempestades en San Sebastián, etc.- poesía -abundante documentación sobre los certámenes poéticos de los Jesuitas en Valencia- pastorales diocesanas y abundante material librario -obras de Alfonso Carrillo Lasso, Diego de Torres Villarroel, Luis de Pragas Bafán, Eugenio Gerardo Lobo, etc. que debieran estar en la Biblioteca, etc.

En conclusión, la colección de P.V. es una sección facticia que, dado su interesante conjunto documental, inédito en gran medida, merece ser consultada por investigadores no sólo vinculados a la historia universitara, sino también por estudiosos de otras especialidades para la España de los Austrias y los primeros Borbones, y que se caracteriza por ser mayoritariamente impresa, aunque con un gran porcentaje de manuscritos, en castellano o latín, cronológicamente de los siglos XVIII o XVII, ofertando como data tópica muy diversos sitios, aunque con predominio de Madrid, Salamanca y Roma, de procedencia mayoritariamente conventual, y de temática jesuítica, dominica o universitaria preferentemente.

Extraemos a continuación un resumen de los caracteres internos y externos de la colección:

33. Vid. LORENZO CADARSO, P.L. Rodrigo Fuenmayor, un arbitrista del s. XVII. Logroño, 1999. Investigación basada en documentos de nuestra Colección. 
PAPELES VARIOS DEL ARCHIVO HISTÓRICO DE LA UNIVERSIDAD DE SALAMANCA

\begin{tabular}{|c|c|c|c|c|}
\hline \multicolumn{5}{|c|}{ CARACTERES DE LA COLECCIÓN } \\
\hline \multicolumn{5}{|c|}{ Caracteres externos } \\
\hline \multirow[b]{2}{*}{ Clase } & \multicolumn{2}{|c|}{$\begin{array}{l}\text { Documentos textuales, que transmiten la } \\
\text { información mediante texto escrito }\end{array}$} & \multicolumn{2}{|c|}{$\begin{array}{l}\text { - Impresos } \\
\text { - Manuscritos }\end{array}$} \\
\hline & \multicolumn{2}{|c|}{$\begin{array}{l}\text { Documentos iconográficos, que emplean la } \\
\text { imagen y signos no textuales para representar } \\
\text { la información }\end{array}$} & \multicolumn{2}{|c|}{$\begin{array}{l}\text { - Dibujos } \\
\text { - Grabados } \\
\text { - Mapas }\end{array}$} \\
\hline Tipo & \multicolumn{2}{|c|}{$\begin{array}{l}\text { Abundante tipología documental, producto de la } \\
\text { reunión de infinitud de testimonios de diversas } \\
\text { actividades }\end{array}$} & \multicolumn{2}{|c|}{$\begin{array}{l}\text { - Documentación cortesana (Provisiones } \\
\text { Reales, Sobrecartas, Reales Cédulas, } \\
\text { Pragmáticas Reales, etc.) } \\
\text { - Documentación pontificia (Bulas, } \\
\text { Privilegios, Cartas Apostólicas, Breves y } \\
\text { Motupropios) } \\
\text { - Documentación judicial (documentos } \\
\text { expedidos por tribunal -dispositivos, } \\
\text { probatorios y de oficio expedidos por los } \\
\text { litigantes -dispositivos, probatorios, } \\
\text { denunciatorios, peticionarios y alegatorios) } \\
\text { - Documentación privada: correspondencia, } \\
\text { consultas, etc. } \\
\text { - Otra documentación (Universidades, } \\
\text { Ordenes religiosas, etc.) } \\
\text { - Abundante material bibliográfico }\end{array}$} \\
\hline Formato & \multicolumn{2}{|c|}{$\begin{array}{l}\text { Presencia de diversos tamaños de unidades de } \\
\text { instalación y de agrupaciones documentales }\end{array}$} & \multicolumn{2}{|c|}{$\begin{array}{l}\text { - } 143 \text { Volúmenes (predominan en } 4^{\circ} \text { y en } 8^{o} \text { ) } \\
\text { - } 63 \text { Legajos (predominan en } 4^{\circ} \text { y en } 8^{o} \text { ) }\end{array}$} \\
\hline Cantidad & \multicolumn{2}{|l|}{279 unidades de instalación } & \multicolumn{2}{|c|}{$\begin{array}{l}\text { - Presentes } 206 \\
\text { - Ausentes } 73\end{array}$} \\
\hline Forma & \multicolumn{2}{|c|}{$\begin{array}{l}\text { Diferentes tradiciones documentales o diversos } \\
\text { modos de transmisión de los documentos }\end{array}$} & \multicolumn{2}{|c|}{$\begin{array}{l}\text { - Minutas } \\
\text { - Originales } \\
\text { - Copias } \\
\text { - Categorías intermedias }\end{array}$} \\
\hline & \multicolumn{4}{|c|}{ Caracteres internos } \\
\hline \multirow[b]{2}{*}{$\begin{array}{l}\text { Entidad } \\
\text { productora }\end{array}$} & \multirow[t]{2}{*}{ Diversidad de procedencias } & \multicolumn{2}{|c|}{ Procedencia conventual } & $\begin{array}{l}\text { - Jesuitas } \\
\text { - Dominicos } \\
\text { - Otras (Franciscanos, Cistercienses } \\
\text { y Agustinos Calzados) }\end{array}$ \\
\hline & & \multicolumn{2}{|c|}{ Procedencia no conventual } & $\begin{array}{l}\text { - Colegio Mayor de Cuenca } \\
\text { - Lorenzo Velasco } \\
\text { - Colegio Mayor de Santiago el } \\
\text { Zebedeo } \\
\text { - Otras (Obispado de Salamanca, } \\
\text { etc.) }\end{array}$ \\
\hline $\begin{array}{l}\text { Orígenes } \\
\text { funcionales }\end{array}$ & \multicolumn{4}{|c|}{$\begin{array}{l}\text { Múltiples razones por las que se han producido los documentos, debido a la diversidad de } \\
\text { funciones, actividades y trámites por los que han sido realizados. Dicha multiplicidad conlleva } \\
\text { la inexistencia de series documentales. }\end{array}$} \\
\hline
\end{tabular}




\begin{tabular}{|c|c|c|c|}
\hline Data crónica & \multicolumn{2}{|c|}{$\begin{array}{l}\text { Presencia de agrupaciones documentales desde } \\
\text { el s. XVI hasta el s. XIX. }\end{array}$} & $\begin{array}{l}\text { - Predominio de documentos de los } \\
\text { siglos XVIII y XVII, por este orden. } \\
\text { - Documentos marginales de los siglos } \\
\text { XIX y XVI. } \\
\text { - Centro neurálgico cronológico en la } \\
\text { primera mitad del s. XVIII }\end{array}$ \\
\hline Data tópica & \multicolumn{2}{|c|}{$\begin{array}{l}\text { Presencia de agrupaciones documentales datados } \\
\text { en el territorio perteneciente a la Monarquía } \\
\text { Española durante los siglos XVII y XVIII, } \\
\text { esencialmente. }\end{array}$} & $\begin{array}{l}\text { - Predominio de Madrid, Salamanca y } \\
\text { Roma. } \\
\text { - Presencia no minoritaria de abundantes } \\
\text { lugares (Sevilla, Valencia, Lisboa, } \\
\text { Valladolid, París, etc.). } \\
\text { - Presencia de documentos datados en } \\
\text { Indias y Filipinas } \\
\text { - Carácter cosmomopolita de la colección }\end{array}$ \\
\hline Idioma & \multicolumn{2}{|c|}{$\begin{array}{l}\text { Presencia de diversas lenguas, con predominio } \\
\text { del castellano. }\end{array}$} & $\begin{array}{l}\text { - Castellano } \\
\text { - Latín } \\
\text { - Portugués } \\
\text { - Italiano } \\
\text { - Francés } \\
\text { - Otros (catalán, griego y chino) }\end{array}$ \\
\hline & 1. Contenidos específicos & \multicolumn{2}{|c|}{$\begin{array}{l}\text { - Temas concernientes a la Orden de los Predicadores. } \\
\text { - Temas concernientes a la Compañía de Jesús. } \\
\text { - Temas concernientes a la Universidad de Salamanca }\end{array}$} \\
\hline & 2. Contenidos preferentes & \multicolumn{2}{|c|}{$\begin{array}{l}\text { - Sermones y oraciones fúnebres y panegíricas. } \\
\text { - Restauraçao portuguesa y la Secesión de Portugal en } 1640 . \\
\text { - Sátira política y religiosa. } \\
\text { - La ciudad de Salamanca y su entorno. } \\
\text { - Temática festiva. } \\
\text { - Universidades y Colegios. }\end{array}$} \\
\hline $\begin{array}{l}\text { Contenido } \\
\text { sustantivo }\end{array}$ & 3. Otros contenidos & \multicolumn{2}{|c|}{$\begin{array}{l}\text { - Asuntos de marcado carácter internacional (asuntos } \\
\text { relativos a Portugal, Francia, Escocia, Inglaterra, Filipinas, } \\
\text { China e Indias Orientales, Indias españolas, etc.) } \\
\text { - Conflictos jurídicos de diversa naturalesza y pleitos. } \\
\text { - Documentación cortesana relativa a diversos asuntos } \\
\text { económicos y sociales del momento. } \\
\text { - Documentación pontificia acerca de privilegios, } \\
\text { consultas, relaciones Iglesia-Estado, etc. } \\
\text { - Abundantes contenidos específicos sobre religiosidad } \\
\text { y mentalidades. } \\
\text { - Temática arbitrista de distintos méritos e interés histórico. } \\
\text { - Otras temáticas de enorme interés: historia de las } \\
\text { minorías, temática inquisitorial, genealogías, asuntos } \\
\text { concernientes a otras ciudades, etc. }\end{array}$} \\
\hline
\end{tabular}

